\title{
High prevalence of pain among adult HIV-infected patients at University of Gondar Hospital, Northwest Ethiopia
}

This article was published in the following Dove Press journal: Journal of Pain Research

13 October 2017

Number of times this article has been viewed

\author{
Abere Woretaw Azagew' \\ Hiwot Kassa Woreta' \\ Ambaye Dejen Tilahun ${ }^{2}$ \\ Degefaye Zelalem Anlay ${ }^{3}$ \\ 'Department of Medical Nursing, \\ ${ }^{2}$ Emergency and Critical Nurse \\ Unit, ${ }^{3}$ Community Health Unit, \\ College of Medicine and Health \\ Science, University of Gondar, \\ Gondar, Ethiopia
}

Background: HIV/AIDS are pressing global health problems. Pain is a common symptom reported by patients living with HIV/AIDS. The exact cause of pain in HIV patients has not been thoroughly described, but it may, due to a symptom of HIV itself, result from opportunistic infections, as a side effect of antiretroviral drugs, concurrent neoplasia or other causes. In addition, pain perception of HIV-infected patients is highly variable and may vary based on cultural context and patient demographics. In Ethiopia, there is insufficient evidence on the prevalence and factors associated with HIV-related pain.

Methods: A cross-sectional study was conducted among 422 adult HIV-infected patients at Gondar University Hospital antiretroviral care clinic from March 1 to May 1, 2016. Systematic random sampling was used to select study participants. A pretested interviewer-administered questionnaire and a standardized medical record data abstraction tool were used to collect data. A short form brief pain inventory tool was used to measure the outcome. Bivariate and multivariate logistic regression models were fitted to identify factors associated with pain among adult HIV patients.

Results: The prevalence of pain was found to be $51.2 \%$ (95\% CI: $46.4 \%-55.9 \%$ ). Headache (17.9\%), abdominal pain (15.6\%), and backache (13.3\%) were the most common symptoms of study participants. Being female (adjusted odds ratio [aOR]=1.8, 95\% CI: $1.1-2.9$ ); regular alcohol intake (aOR=3.3, 95\% CI: 1.5-7.2); baseline World Health Organization clinical disease stage: II (aOR=2.5, 95\% CI: 1.2-4.9), III (aOR=2, 95\%, CI: $1.1-3.6)$, and IV (aOR=2.4, 95\% CI: $1.1-5.3$ ); and the presence of a chronic comorbid condition ( $\mathrm{aOR}=5.9,95 \% \mathrm{CI}: 2.1-16.7$ ) were significantly associated with pain.

Conclusion: Adult HIV patients in this sample reported a high level of chronic pain. Healthcare providers should better implement a routine pain assessment among HIV-positive patients to alleviate their suffering.

Keywords: human immunodeficiency virus, acquired immune deficiency syndrome, sub-saharan Africa, Ethiopia, pain, prevalence

\section{Introduction}

HIV and AIDS are among the most devastating health problems throughout the world and especially in developing countries. It is estimated that there are 36.7 million people living with HIV/AIDS and that 1.1 million die annually of AIDS-related illnesses. SubSaharan Africa remains one of the most severely affected regions accounting for nearly $70 \%$ of the people living with HIV worldwide. ${ }^{1}$ In Ethiopia, the national adult HIV/ AIDS prevalence has been reported to be $1.14 \%{ }^{2}$ It has been estimated that 542,121
Correspondence: Abere Woretaw Azagew

Department of Medical Nursing, College of Medicine and Health Science, University of Gondar, PO Box 196,

Gondar, Ethiopia

Email wabere@ymail.com 
adults and 178,500 children require antiretroviral treatment in Ethiopia. ${ }^{3}$ In addition to the immune dysfunction resulting from HIV/AIDS infection, patients also suffer from a range of other symptoms, including pain. Pain has been defined as "an unpleasant sensory and emotional experience associated with actual or potential tissue damage. Many people report pain in the absence of tissue damage or any pathophysiological change". ${ }^{4}$ Pain can occur across the clinical stages of HIV disease but is believed to increase in severity and intensity as HIV disease progresses. Reasons for HIV-related pain have not been fully established, but it may be a symptom of HIV disease, resulting from other illness or infections - including opportunistic infections - that occur as a side effect of antiretroviral drugs, concurrent neoplasia or other cause.,

HIV-related chronic pain is commonly associated with peripheral receptor hypersensitization by inflammation or central sensitization in which the brain receives strong signals of pain. HIV-related pain can affect different anatomic sites. ${ }^{7}$ Peripheral neuropathy, headache, abdominal pain, joint pain muscle pain, bone pain and herpes-related pain are common types of HIV-related pain. ${ }^{6}$ Previous reports have estimated that $39 \%-85 \%$ of individuals with HIV infection suffer from chronic pain compared with only $20 \%-30 \%$ of general population. ${ }^{8}$ Geographic and cultural variations in reports of pain in HIV/AIDS patients have been reported. ${ }^{7}$ In India, the prevalence of pain was $66.7 \%$ in in-patients and $24.5 \%$ in out-patients. Pain in the sole of feet and low back pain were the common complaints next to headache. ${ }^{9}$ In the USA, a study among HIV-infected women showed that $27.4 \%$ had infrequent pain, $25.7 \%$ frequent pain and $20.4 \%$ highly frequent pain, while $10 \%$ reported daily pain or pain that lasted 120 days. ${ }^{10}$ In Nigeria, pain was reported in $83.7 \%$ of patients and in patients with pain impacted patients' functioning, including general activity (86.7\%), mood (89.9\%), sleep pattern (73.4\%) and work activities $(83 \%) .{ }^{11}$ Other studies have shown that pain results in sleep disturbance and functional limitations. ${ }^{12}$ Using a standardized pain assessment, patients in Uganda reported pain as mild $(53 \%)$, moderate $(20 \%)$ and severe $(27 \%))^{13}$

Acute (lasting weeks or fewer weeks) or chronic pain (lasting weeks or more) can lower the quality of life and, in severe cases, profoundly disrupt the ability to engage in day-to-day activities. In HIV/AIDS patients, pain causes both short- and long-term emotional and mental health distress. ${ }^{14}$

Pain has been associated with age, ${ }^{15}$ female sex, lower educational status, ${ }^{16}$ single marital status, ${ }^{17}$ history of smoking, ${ }^{10}$ lower CD4 count, ${ }^{10,15,18,19}$ longer duration of HIV infection and treatment with antiretroviral medications, including longer duration of antiretroviral treatment (ART),${ }^{20}$ particularly protein inhibitor-based regimens, ${ }^{21}$ use of ART, ${ }^{19}$ advanced disease stage and the number of health comorbidities. ${ }^{13,22}$

However, HIV/AIDS patients are heterogeneous and HIV/AIDS can occur with a variety of comorbid conditions resulting in pain. ${ }^{22}$

Furthermore, the perception of pain may vary across different cultures, so there is an urgent need to describe HIV/ AIDS-related pain across settings. In order to address the gap in understanding the prevalence of HIV-related pain and its associated factors in Ethiopia, the aim of this study was to evaluate the frequency and associated factors for pain in HIV/AIDS patients.

\section{Methods}

\section{Study design and setting}

A cross-sectional study was conducted to assess the prevalence of self-reported pain and associated factors of pain among adult HIV-infected patients. The study was conducted at the University of Gondar Hospital ART clinic from March 1 to May 1, 2016.

Gondar is a historic city located in Northwest Ethiopia, approximately about $750 \mathrm{~km}$ to the northwest of Addis Ababa. Gondar Hospital is a teaching and referral hospital that serves as the tertiary referral center for $>5$ million people. Started in 2005, ART services currently include 4 outpatient clinics, 1 ART drug refill service and pre-ART evaluation clinic, a comprehensive testing and counseling program as well as a dedicated pharmacy and laboratory services. More than 7500 adults and 700 pediatric HIV-infected patients have been enrolled in HIV care since services began and $>5100$ adult HIV-infected patients are actively followed. The clinics use international guidelines for initiation and management of ART. During the study period, these included CD4 $<500 \mathrm{cell} / \mathrm{mm}^{3}$, World Health Organization (WHO) clinical disease stage, pregnant, laboring, delivery and lactating women and all $<15$ years children. HIV-infected patients who did not fulfill the eligibility criteria had a regular follow-up every 3 months through the pre-ART register.

\section{Study participants}

All HIV-positive adult patients who had been seen at least once prior to the data collection period were included. Patients who had recent surgery or trauma were excluded. 


\section{Ethical statement}

The study was approved by the College of Medicine and Health Sciences Research and Ethical committee and the Institutional Review Board of the University of Gondar with Approval reference number of N/S 863/7/08 E.C. Verbal informed consent was obtained from participants. No personal identifying information, (names, date of birth, patient ID number) were recorded on the tool. Data collection tools and electronic databases were stored in a locked storage area on a secure server.

\section{Sample size and sampling technique}

The sample size was determined by using single population proportion formula through Epi Info StatCalc program with the assumption of $95 \%$ level of confidence and $5 \%$ marginal error and by taking prevalence of pain among HIV patients at Uganda $47 \% .^{13}$

With these assumptions, the sample size became 383 . Anticipating a $10 \%$ non-response rate, the required sample size was 422 . In the ART clinic, there were around 5100 adult HIV-infected patients who had regular follow-up every 2 months. k-value was determined by dividing the total number of adult HIV-infected patients to sample size (12), allocating randomly from 1 to 12 to determine the starting unit (2) then after arranging the patients based on the order of coming to the clinic, each study participant was selected every 12 interval using systematic random sampling.

\section{Data collection tools and procedures}

The data collection questionnaire had 4 parts collecting information on sociodemographic characteristics, personalityrelated characteristics, clinical and treatment factors and the short form of the brief pain inventory (BPI) tool. The BPI assesses pain prevalence, intensity and level of functional interference in HIV-positive patients. It has been shown to have good internal validity and reliability (Cronbach's $\alpha=0.77$ [pain severity] and 0.83 [pain interference]) for the pain severity and pain interference subscales, respectively. ${ }^{13,23}$ The BPI assesses pain intensity using a 0-10 numerical rating scale. Patients without pain (0 score) over the past 24 hours were categorized as "no pain", and those with pain score (1-10) were categorized as "having pain". Based on prior research, pain/functional interference was classified as "mild/mild interference" (numeric rating scale [NRS] 1-4), "moderate/moderate interference" (NRS 5-6) or "severe/ severe interference" (NRS 7-10). The BPI tool also assesses the functional interference of pain using psychometric measures (general activity, mood, walking ability, normal work, relations with other people and enjoyment of life) and to mark the anatomic location of pain. ${ }^{13,23,24}$ The instrument was translated from English into Amharic and reverse translated into English to ensure conceptual integrity.

Data were collected by 4 trained and experienced HIV/ ART-licensed nurses who received an overview of the study protocol and data collection methods. Fidelity to the data collection protocol was monitored by the supervisor who had regular meetings with the principal investigator at the end of each day of the data collection period. Interim data quality reports were monitored at least weekly by the principal investigator.

\section{Data processing and analysis}

Data were checked, coded, and entered into Epi Info (V. 7) and was exported to SPSS (V.20; IBM, Armonk, NY, USA) for analysis. Descriptive statistics were generated, including frequency, percentage, mean, median, SD and interquartile range (IQR). Anatomic locations were coded by trained data collectors to identify the location of pain.

Binary logistic regression was used to identify factors associated with pain. For factors significant at $p<0.2$ in the binary logistic regression, a multivariable logistic regression model was fitted to control the possible effect of confounders. For the univariable logistic regression, crude odds ratio and $95 \%$ CIs and for the multivariable logistic regression, an adjusted odds ratio (aOR) and 95\% CI were calculated. Variables having a $p$-value of $<0.05$ in the multivariate logistic regression model was considered as statistically significant and independently associated with the dependent variable. A backward stepwise regression was used as a variable selection method. Model fitness was checked by using Hosmer and Lemeshow goodness of fit test.

\section{Results \\ Sociodemographic characteristics of respondents}

All 422 HIV-infected patients participated in the study. More than half, 251 (59.5\%), of the respondents were females. The median age of the respondents (IQR) was $37(30-45)$ years. Among study participants, 182 (43.1\%) were married and 373 (88.4\%) were Christians. Majority (87.9\%) of the respondents lived in urban and $346(82 \%)$ were Amhara by ethnicity. One hundred eighteen (28\%) of the respondents had completed their primary school. More than two-thirds ( $81.3 \%)$ were selfemployed and 146 (34.6\%) had medium income. Ten (2.4\%) of the study participants smoked cigarettes. Eight (80\%) of the smokers smoked for $>5$ years. Forty-three $(10.2 \%)$ drank alcohol regularly (Table 1 ). 
Table I Sociodemographic and personal related variables of HIV-infected adult patients attending at ART care clinic, Gondar University Hospital, 2016 ( $n=422)$

\begin{tabular}{|c|c|c|c|}
\hline \multicolumn{2}{|c|}{ Variables category } & \multirow{2}{*}{$\begin{array}{l}\text { Frequency (n) } \\
|7|\end{array}$} & \multirow{2}{*}{$\frac{\%}{40.5}$} \\
\hline Sex & Male & & \\
\hline & Female & 251 & 59.5 \\
\hline Age group & $18-33$ & 144 & 34.1 \\
\hline \multirow[t]{2}{*}{ (years) } & $34-49$ & 214 & 50.7 \\
\hline & $\geq 50$ & 64 & 15.2 \\
\hline \multirow[t]{4}{*}{ Marital status } & Single & 78 & 18.5 \\
\hline & Married & 182 & 43.1 \\
\hline & Divorced & 106 & 25.1 \\
\hline & Widowed & 56 & 13.3 \\
\hline \multirow[t]{2}{*}{ Religion } & Christian & 373 & 88.4 \\
\hline & Muslim & 49 & 11.6 \\
\hline \multirow[t]{2}{*}{ Residency } & Urban & 371 & 87.9 \\
\hline & Rural & 51 & 12.1 \\
\hline \multirow[t]{4}{*}{ Ethnicity } & Amhara & 346 & 82 \\
\hline & Kimant & 50 & 11.8 \\
\hline & Tigray & 19 & 4.5 \\
\hline & Other & 7 & 1.7 \\
\hline Level of & Unable to read and write & 97 & 23 \\
\hline \multirow[t]{3}{*}{ education } & Informal education & 52 & 12.3 \\
\hline & Primary school & 118 & 28 \\
\hline & High school and above & 155 & 36.7 \\
\hline \multirow[t]{2}{*}{ Occupation } & Government employed & 79 & 18.7 \\
\hline & Self employed & 343 & 81.3 \\
\hline \multirow[t]{3}{*}{ Income } & Low income & 140 & 33.2 \\
\hline & Medium income & 146 & 34.6 \\
\hline & High income & 136 & 32.2 \\
\hline \multirow[t]{2}{*}{ Smoking } & Smoker & 10 & 2.4 \\
\hline & Nonsmoker & 412 & 97.6 \\
\hline Number of & $\leq 5$ & 5 & 50 \\
\hline cigarettes/day & $>5$ & 5 & 50 \\
\hline Duration of & $\leq 5$ & 2 & 20 \\
\hline smoking, year & $>5$ & 8 & 80 \\
\hline Regular alcohol & Yes & 43 & 10.2 \\
\hline drunker & No & 379 & 89.8 \\
\hline Type of alcohol & Beer and "areki" & 28 & 65.1 \\
\hline use & “Local tela" & 15 & 34.9 \\
\hline Duration of & $\leq 5$ & 19 & 44.2 \\
\hline $\begin{array}{l}\text { alcohol intake } \\
\text { (years) }\end{array}$ & $>5$ & 24 & 55.8 \\
\hline
\end{tabular}

Note: "Other" at ethnicity - Oromo and Guragie.

Abbreviation: ART, antiretroviral treatment.

\section{Clinical and treatment-related characteristics of respondents}

The median duration of a patient living with HIV since first confirmation was 74 months with an IQR of 72 months. More than half (59.2\%) of the respondents had a baseline CD4 count of $\leq 200$ cells $/ \mathrm{mm}^{3}$. Nearly half of the respondents (51.4\%) had WHO clinical disease stage III at the time of enrollment. Most of the respondents (92.7\%) were on ART with a median (IQR) duration of 72 (70 months). Regarding the type of regimen, $129(33 \%)$ were on zidovudine (AZT), lamivudine (3TC) and nevirapine (NVP)-based regimen (Table 2).

\section{Prevalence of pain}

A total of 216 adult HIV patients complained about pain that gave a $51.2 \%(46.4 \%-55.9 \%)$ of pain prevalence. The parts of the body commonly involved were the head 47 (17.9\%) followed by the abdomen 41 (15.6\%) and the back 35 (13.3\%) (Table 3).

Table 2 Clinical and treatment-related characteristics of HIVinfected adult patients attending at ART care clinic, Gondar University Hospital, 2016 ( $n=422)$

\begin{tabular}{|c|c|c|c|}
\hline \multicolumn{2}{|l|}{ Variables category } & \multirow{2}{*}{$\begin{array}{l}\text { Frequency (n) } \\
204\end{array}$} & \multirow{2}{*}{$\begin{array}{l}\% \\
48.3\end{array}$} \\
\hline Total duration & $\leq 72$ & & \\
\hline $\begin{array}{l}\text { since HIV } \\
\text { confirmed } \\
\text { (months) }\end{array}$ & $>72$ & 218 & 51.7 \\
\hline Baseline CD4 & $\leq 200$ & 250 & 59.2 \\
\hline \multirow[t]{2}{*}{ count (cells $/ \mathrm{mm}^{3}$ ) } & $201-499$ & 155 & 36.7 \\
\hline & $\geq 500$ & 17 & 4.1 \\
\hline CD4 count at ART & $\leq 200$ & 226 & 57.8 \\
\hline $\begin{array}{l}\text { initiation } \\
\text { (cells } / \mathrm{mm}^{3} \text { ) }\end{array}$ & $>200$ & 165 & 42.2 \\
\hline The most recent & $\leq 200$ & 91 & 21.6 \\
\hline CD4 count & $201-499$ & 203 & 48.1 \\
\hline$\left(\right.$ cells $\left./ \mathrm{mm}^{3}\right)$ & $\geq 500$ & 128 & 30.3 \\
\hline Baseline WHO & 1 & 73 & 17.3 \\
\hline \multirow[t]{3}{*}{ clinical stage } & II & 81 & 19.2 \\
\hline & III & 217 & 51.4 \\
\hline & IV & 51 & 12.1 \\
\hline WHO clinical & 1 & 58 & 14.8 \\
\hline stage at ART & II & 80 & 20.5 \\
\hline \multirow[t]{2}{*}{ initiation } & III & 203 & 51.9 \\
\hline & IV & 50 & 12.8 \\
\hline Recent WHO & $\mathrm{I} / \mathrm{II}$ & 371 & 87.9 \\
\hline clinical stage & III/IV & 51 & 12.1 \\
\hline Chronic comorbid & Yes & 25 & 5.9 \\
\hline condition & No & 397 & 94.1 \\
\hline Type of chronic & Hypertension & 7 & 28 \\
\hline comorbid & Diabetes mellitus & 5 & 20 \\
\hline \multirow[t]{4}{*}{ condition } & Chronic kidney disease & 5 & 20 \\
\hline & Glaucoma & 3 & 12 \\
\hline & Asthma & 3 & 12 \\
\hline & Epilepsy & 2 & 8 \\
\hline Opportunistic & Yes & 46 & 10.9 \\
\hline infection & No & 376 & 89.1 \\
\hline Type of & Tuberculosis & 14 & 30.4 \\
\hline opportunistic & Oral candidacies & 8 & 17.4 \\
\hline \multirow[t]{8}{*}{ infection } & Skin rash & 4 & 8.7 \\
\hline & Upper respiratory & 5 & 10.9 \\
\hline & infection & & \\
\hline & Diarrhea & 4 & 8.7 \\
\hline & Post herpetic neuralgia & 3 & 6.5 \\
\hline & Kalazar & 3 & 6.5 \\
\hline & Lymphoma & 2 & 4.4 \\
\hline & Otitis media & 3 & 6.5 \\
\hline
\end{tabular}


Table 2 (Continued)

\begin{tabular}{llll}
\hline Variables category & Frequency (n) & $\%$ \\
\hline ART drug use & Yes & 39 I & 92.7 \\
& No & 31 & 7.3 \\
Duration of ART & $\leq 70$ & 193 & 49.4 \\
use (months) & $>70$ & 198 & 50.6 \\
ART regimen at & D4t-3TC-NVP (Ia) & $5 \mathrm{I}$ & 13 \\
initiation & D4T-3TC-EFV (Ib) & 35 & 9 \\
& AZT-3TC-NVP (Ic) & 129 & 33 \\
& AZT-3TC-EFV(Id) & 42 & 10.7 \\
& TDF-3TC-EFV (Ie) & 102 & 26.1 \\
ART regimen & TDF-3TC-NVP (If) & 32 & 8.2 \\
change & Yes & 116 & 29.7 \\
Current ART & No & 275 & 70.3 \\
regimen & First line & 376 & 96.2 \\
Prophylaxis use & Second line & 15 & 3.8 \\
& Yes & 177 & 41.9 \\
Type of & No & 245 & 58.1 \\
Prophylaxis use & INH & 2 & 1.1 \\
\hline
\end{tabular}

Abbreviation: ART, antiretroviral treatment; D4T, Stavudine; EFV, Efavirenz; TDF, Tenofovir; WHO, World Health Organization NVP, nevirapine; 3TC, lamuvudine; AZT, zidovudine; INH, isoniazaide preventive therapy; CPT, cotrimoxazole preventive therapy

Table 3 Parts of body involved by pain among HIV-infected adult patients attending at ART care clinic, Gondar University Hospital, $2016(n=216)$

\begin{tabular}{lll}
\hline Parts of body involved by pain & Frequency (n) & $\%$ \\
\hline Headache & 47 & 21.7 \\
Abdominal pain & 41 & 18.9 \\
Back pain & 35 & 16.2 \\
Chest pain & 30 & 13.8 \\
Joint pain & 21 & 9.7 \\
Neck pain & 16 & 7.4 \\
Thigh muscle pain & 14 & 6.5 \\
Lip sore & 11 & 5 \\
Shoulder pain & 8 & 3.7 \\
Generalized body itching, pain & 8 & 3.7 \\
Generalized body pain & 7 & 3.2 \\
Upper extremity pain & 7 & 3.2 \\
Foot burning pain & 7 & 3.2 \\
Tooth ache & 5 & 2.3 \\
Itching pain of eye & 3 & 1.4 \\
Post-herpetic neuralgia & 2 & 0.9 \\
\hline Ab
\end{tabular}

Abbreviation: ART, antiretroviral treatment.

\section{Level and functional interference of pain}

The overall level of pain at its worst in the past 24 hours was 4.3 , whereas the overall level of pain at its least in the past 24 hours was 2.9. Regarding the levels of pain at the time of data collection, the mean score was 3.5 (Table 4).

Respondents who had pain in the past 24 hours had different levels of functional interference. Among these, $7.1 \%$ of the respondents were severely affected in their general activities, $6.6 \%$ were moderately affected in their mood, $10.9 \%$ were moderately affected in their walking ability, $15.9 \%$ were moderately affected in their normal work, $13.1 \%$ affected in their sleep pattern and $3.3 \%$ in their enjoyment of life.

Among respondents who had pain, 47 (21.8\%) took analgesic of which $22(45 \%)$ received paracetamol, 17 (38\%) received diclofenac and $8(17 \%)$ received tramadol. After the intake of these analgesics, the mean pain-relieving percentage was $54.9 \% \pm 22.3 \%$ (SD) (Figure 1).

\section{Factors associated with pain}

In the multivariate logistic regression analysis, being female, alcohol intake, WHO clinical disease stages II, III and IV, and chronic comorbid conditions were significantly associated with pain (Table 5).

\section{Discussion}

In this study, the prevalence of pain among adult HIV-infected patients was found to be $51.2 \%$ (95\% CI: 46.4-55.9). The common complaining symptoms were headache $17.9 \%$ followed by the abdominal pain $15.6 \%$ and backache $13.3 \%$. Being female, alcohol intake, WHO clinical stage II and above and presence of comorbid conditions were determinants of chronic pain in HIV-infected adult patients. Age, lower CD4 count, time since diagnosis of HIV infection and receipt of protein inhibitor-based regimen or use of ART were not associated with the presence of pain in the current study. The finding of the study is in line with a study conducted in Uganda (47\%), Botswana (48.7\%) and San Francisco (55\%). ${ }^{13,18,25}$ On the other hand, the magnitude of pain was lower compared with results of studies conducted in the USA (54\%-83\%), Nigeria (83.7\%), San Francisco (91.2\%), South Africa (74.24\%) and the UK $(62.8 \%))^{7,10,11,16,21}$ This could be due to the different instrument used for data collection, variation in data collection period and different study designs. Additionally, it might be attributed to variation in pain perception from individual to individual. To the contrary, the current prevalence is higher compared with those of studies done in South India (24.5\%), Birmingham (34\%), South Africa (22\%) and Nigeria (27.8\%). ${ }^{9,26-28}$ Possibly, this discrepancy might occur due to sociocultural, lifestyle and economic status differences of these countries. ${ }^{29}$

Sex was the determinant factor of pain among people living with HIV/AIDS. The likelihood of pain was higher among female patients compared with male counterparts ( $\mathrm{aOR}=1.8,95 \% \mathrm{CI}: 1.1-2.9)$.The finding is consistent with those other studies in San Francisco and South Africa. ${ }^{16,30}$ The biological differences and susceptibility to infections among women, especially in resource-poor setting, might attribute to this difference. The expression of pain also varies according to the culture and sex of the individuals. ${ }^{31}$ 
Table 4 Level of pain among HIV-infected adult patients attending at ART care clinic, Gondar University Hospital, 2016

\begin{tabular}{lllllll}
\hline Pain description & Pain intensity & Frequency $(\mathbf{n})$ & $\%$ & Overall mean score & Overall pain intensity & SD \\
\hline Worst pain level in the & Mild & 80 & 43.7 & 4.3 & Mild-to-moderate pain \\
past 24 hours & Moderate & 50 & 53 & 27.3 & & Mild pain \\
& Severe & 130 & 29 & 73.4 & 2.9 & Mild pain \\
Least pain level in the & Mild & 32 & 18.1 & & 2.1 \\
past 24 hours & Moderate & 15 & 8.5 & & Mild pain \\
Average pain level in the & Severe & Mild & 112 & 62.2 & 3.3 & \\
past 24 hours & Moderate & 52 & 28.9 & & 2.2 \\
Current pain & Severe & 16 & 8.9 & 3.5 & \\
& Mild & 102 & 53.3 & & 2.4 \\
& Moderate & 49 & 25.5 & & \\
\hline
\end{tabular}

Abbreviation: ART, antiretroviral treatment.

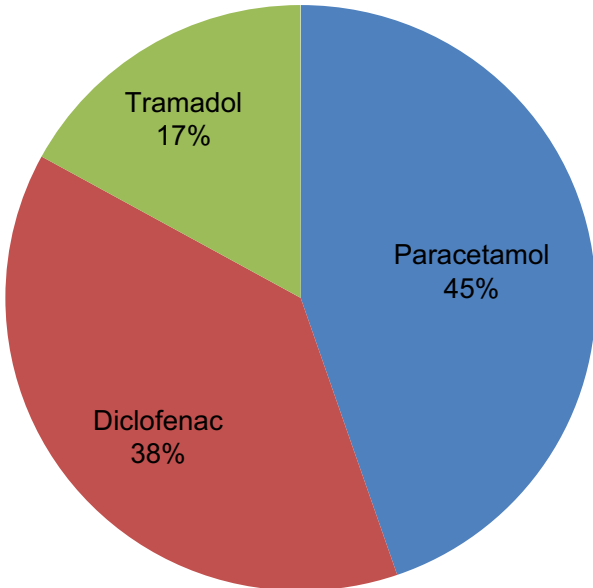

Figure I Prescribed analgesics for pain among HIV-positive adult patients attending at ART care clinic, Gondar University Hospital, 2016.

Abbreviation: ART, antiretroviral treatment.

In this particular study, alcohol intake was an important factor of pain. Adult HIV patients who took alcohol were nearly 3 times more likely to experience pain compared with nonalcohol users ( $\mathrm{aOR}=3.3,95 \% \mathrm{CI}: 1.5-7.2)$. A study conducted in Russia also came up with a similar finding. ${ }^{32}$ This is due to the fact that alcohol intake and HIV suppress the immune system independently and additively, which further result in different infectious diseases with different symptoms, including pain. ${ }^{33,34}$ The study also found that pain was significantly associated with WHO clinical disease stage II and above. This finding is supported by other studies done in the US, London and South Africa. ${ }^{10,18,20,35}$ This could be due to the fact that WHO clinical disease stage is an important indicator of disease progression indicating the presence of opportunistic infection that leads to experience of pain. ${ }^{36}$ In this study, having chronic comorbid condition was also found to be another determinant factor of pain among HIV-infected patients. HIV-infected patients with chronic comorbid condition were nearly 6 times more likely to have pain compared with patients without chronic comorbid conditions (aOR=5.9, 95\% CI: 2.1-16.7). This finding is also supported by other studies in Uganda, San Francisco and Botswana. ${ }^{13,18,35}$

The presence of chronic comorbid condition might increase disease progression leading to pain. In addition to this, chronic comorbid condition and its management might result in pain. ${ }^{37} \mathrm{~A}$ short-term BPI tool was used but that failed to identify the types of pain (nociceptive or neuropathic pain), and further research on the type of pain and the adequacy of analgesic therapy is recommended.

\section{Conclusion}

The prevalence of pain was found to be high. Being female, alcohol intake, the presence of chronic comorbid condition and WHO clinical stage II and above were significantly associated with pain prevalence. Hence, health-care providers should better implement a routine pain assessment to HIVpositive patients to alleviate from their suffering. For better understanding, conducting additional researches on specific causes, types, and intensity and management modalities of pain is important.

\section{Clinical implication}

Pain is a common symptom among adult people living with HIV/AIDS, particularly in patients who had advanced WHO clinical disease stages.

Pain was not associated with CD4 count or ART therapy but was significantly associated with WHO disease classification.

Routine pain assessment must be performed in highrisk patient (like patient with history of comorbid condition and alcohol intake) to determine severity, impact of pain on functional abilities and quality of life. 
Table 5 Factors associated with pain among HIV-infected adult patients attending at ART care clinic, Gondar University Hospital, 2016 $(\mathrm{n}=422)$

\begin{tabular}{|c|c|c|c|c|}
\hline \multirow[t]{2}{*}{ Variables } & \multicolumn{2}{|c|}{ Pain } & \multirow[t]{2}{*}{ Crude OR } & \multirow[t]{2}{*}{ Adjusted OR } \\
\hline & Yes & No & & \\
\hline \multicolumn{5}{|l|}{ Sex } \\
\hline Male & 86 & 85 & I & I \\
\hline Female & 130 & $|2|$ & $1.062(0.720-1.566)$ & $1.785(1.112-2.866)^{*}$ \\
\hline \multicolumn{5}{|l|}{ Age group (years) } \\
\hline $18-33$ & 69 & 75 & I & I \\
\hline $34-49$ & 107 & 107 & $\mathrm{I} .087(0.7 \mathrm{I} 2-\mathrm{I} .659)$ & $\mathrm{I} .068(0.644-\mathrm{I} .772)$ \\
\hline$\geq 50$ & 40 & 24 & $1.812(0.992-3.309)$ & $1.922(0.92-4.012)$ \\
\hline \multicolumn{5}{|l|}{ Marital status } \\
\hline Single & 38 & 40 & I & I \\
\hline Married & 90 & 92 & $1.030(0.606-1.75 \mathrm{I})$ & I.534 (0.837-2.8I) \\
\hline Divorced & 62 & 44 & $\mathrm{I} .483(0.823-2.672)$ & 1.799 (0.919-3.519) \\
\hline Widowed & 26 & 30 & $0.912(0.459-1.815)$ & $0.984(0.445-2.174)$ \\
\hline \multicolumn{5}{|l|}{ Address } \\
\hline Urban & 187 & 184 & I & I \\
\hline Rural & 22 & 29 & $\mathrm{I} .297(0.297-2.34 \mathrm{I})$ & $0.917(0.434-1.937)$ \\
\hline \multicolumn{5}{|l|}{ Level of education } \\
\hline Unable to read and write & 57 & 40 & $1.44(0.865-2.410)$ & $1.039(0.576-1.874)$ \\
\hline Informal education & 30 & 22 & 1.38 (0.733-2.609) & $0.935(0.452-1.936)$ \\
\hline Primary school & 52 & 66 & $0.798(0.493-1.291)$ & $0.73(0.423-1.259)$ \\
\hline High school and above & 77 & 78 & I & I \\
\hline \multicolumn{5}{|l|}{ Occupation } \\
\hline Government employed & 36 & 43 & I & I \\
\hline Self-employed & 180 & 163 & $1.319(0.807-2.155)$ & I.II2 (0.583-2.12I) \\
\hline \multicolumn{5}{|l|}{ Alcohol intake } \\
\hline Yes & 30 & 13 & $2.395(1.212-4.732)$ & $3.298(1.517-7.167)^{*}$ \\
\hline No & 186 & 193 & I & $\mathrm{I}$ \\
\hline \multicolumn{5}{|c|}{ Baseline CD4 count (cells/mm³) } \\
\hline$\leq 200$ & 124 & 126 & I.329 (0.858-2.059) & 1.467 (0.898-2.397) \\
\hline $201-350$ & 68 & 52 & $8.87 \mid(0.479-I .585)$ & $1.202(0.60 \mathrm{I}-2.403)$ \\
\hline$\geq 350$ & 24 & 28 & 1 & I \\
\hline \multicolumn{5}{|c|}{ The most recent CD4 count (cells/mm $\left.\mathrm{mm}^{3}\right)$} \\
\hline$\leq 200$ & 52 & 39 & $1.770(1.028-3.046)$ & $1.215(0.552-2.674)$ \\
\hline $201-499$ & 109 & 94 & $1.539(0.986-2.403)$ & I.197 (0.69-2.076) \\
\hline$\geq 500$ & 55 & 73 & I & 1 \\
\hline \multicolumn{5}{|c|}{ Baseline WHO clinical stage } \\
\hline 1 & 26 & 47 & 1 & 1 \\
\hline II & 46 & 35 & $2.376(1.240-4.552)$ & $2.45 \mathrm{I}(1.228-4.89 \mathrm{I})^{*}$ \\
\hline III & 116 & 101 & $2.076(1.200-3.592)$ & $1.996(1.105-3.605)^{*}$ \\
\hline IV & 28 & 23 & $2.201(1.060-4.569)$ & $2.379(1.078-5.253)^{*}$ \\
\hline \multicolumn{5}{|c|}{ Most recent WHO clinical stage } \\
\hline $\mathrm{I} / \mathrm{II}$ & 184 & 187 & I & I \\
\hline III/IV & 32 & 19 & $1.712(0.937-3.128)$ & $0.828(0.368-1.86)$ \\
\hline \multicolumn{5}{|c|}{ Total duration since HIV confirmed (months) } \\
\hline$\leq 72$ & 106 & 98 & 1 & I \\
\hline$>72$ & 110 & 108 & $0.942(0.643-1.38)$ & I.I2I (0.688-I.828) \\
\hline \multicolumn{5}{|l|}{ Comorbid condition } \\
\hline Yes & 20 & 5 & $4.102(1.510-11.145)$ & $5.883(2.068-16.736)^{*}$ \\
\hline No & 196 & 201 & I & 1 \\
\hline \multicolumn{5}{|l|}{ ART user } \\
\hline Yes & 200 & 191 & $0.982(0.472-2.04 I)$ & $1.866(0.695-5.01)$ \\
\hline No & 16 & 15 & I & \\
\hline \multicolumn{5}{|l|}{ Prophylaxis use } \\
\hline Yes & 103 & 74 & $1.626(1.101-2.402)$ & $1.519(0.991-2.329)$ \\
\hline No & 113 & 132 & I & I \\
\hline
\end{tabular}

Note: *Statistically significant.

Abbreviations: ART, antiretroviral treatment; OR, odds ratio; WHO, World Health Organization. 


\section{Acknowledgment}

The authors thank the study participants and data collectors for their collaboration during the data collection. They acknowledge Dr Timothy Landers for his review and input in the manuscript.

\section{Author contributions}

AW conceived the idea and wrote the proposal, participated in the data collection process, analyzed the data and drafted the paper. HK, DZ and AD approved the proposal with some revisions, participated in data analysis and reviewed the manuscript. All authors revised the paper critically and approved the final draft of the manuscript.

\section{Disclosure}

The authors report no conflicts of interest in this work.

\section{References}

1. World Health Organization. [webpage on the Internet]. Global Health Observtory (GHO) dat, HIV/AIDS Available from http://www.who. int/gho/hiv/en/. Accessed October 3, 2017.

2. World Health Organization. [webpage on the Internet]. Ethiopia. Available from http://www.who.int/countries/eth/en/. Accessed October 3, 2017.

3. AIDSFree. [webpage on the Internet]. Ministry of Health. National Comprehensive HIV Care and Treatment Training for Health care Providers. Ethiopia. Available from https://aidsfree.usaid.gov/resources/ ethiopia-national-guidelines-comprehensive-hiv-prevention-care-andtreatment. Accessed October 3, 2017.

4. IASP. [webpage on the Internet]. International association for the study of pain. IASP Taxonomy. Available from https://www.iasp-pain.org/ Taxonomy. Accessed October 3, 2017.

5. Carr, DB. Pain in HIV is a major global health Care problem. Pain in $H I V$ is a major global healthcare problem. Available from https://www. iasp-pain.org/files/Content/ContentFolders/GlobalYearAgainstPain2/2 0042005RighttoPainRelief/paininhivaids.pdf.

6. The well project. [webpage on the Internet]. HIV related pain. Available from http://www.thewellproject.org/hiv-information/hiv-related-pain. Accessed October 3, 2017.

7. Parker R, Stein DJ, Jelsma J. Pain in people living with HIV/AIDS: a systematic review. J Int AIDS Soc. 2014;17(1):18719.

8. Merlin JS. Chronic pain in patients with HIV infection: what clinicians need to know. Top Antivir Med. 2015;23(3):120-124.

9. Nair SN Mary TR, Prathana S, Harrison P. Prevalence of pain in patients with HIV/AIDS: a cross-sectional survey in a South Indian State. Indian $J$ Palliat Care. 2009;15(1):67-70.

10. Richardson JL, Heikes B, Karim R, Weber K, Anastos K, Young M. Experience of pain among women with advanced HIV disease. AIDS Patient Care STDS. 2014;23(7):503-511.

11. Ebirim LN, Otokwala JG. Inadequate pain relief in ambulatory patients with human immunodeficiency virus disease in Port Harcourt. HIV AIDS (Auckl). 2013;5:199-203.

12. Sandoval R, Roddey T, Giordano TP, Mitchell K, Kelley C. Pain, sleep disturbances, and functional limitations in people living with HIV/ AIDS-associated distal sensory peripheral neuropathy. $J$ Int Assoc Provid AIDS Care. 2014;13(4):328-334.

13. Namisango E, Harding R, Atuhaire L, et al. Pain among ambulatory HIV/AIDS patients: multicenter study of prevalence, intensity, associated factors, and effect. $J$ Pain. 2012;13(7):704-713.

14. UNAIDS. Global factsheet, World AIDS day 2012. Available from http://files.unaids.org/en/media/unaids/contentassets/documents/ epidemiology/2012/gr2012/20121120_FactSheet_Global_en.pdf.
15. Tsao JC, Soto T. Pain in persons living with HIV and comorbid psychological and substance use disorders. Clin J Pain. 2009;25(4): 307-312.

16. Miaskowski C, Penko JM, Guzman D, Mattson JE, Bangsberg DR, Kushel MB. Occurrence and characteristics of chronic pain in a community-based cohort of indigent adults living with HIV infection. J Pain. 2011;12(9):1004-1016.

17. Makerere University Institutional Repository. [webpage on the Internet]. Namisango E. Prevalence of and factors associated with pain in ambulatory HIV and AIDS patients at the two teaching and referral Hospitals in Uganda. Available from http://dspace.mak.ac.ug/handle/10570/3421. Accessed October 3, 2017.

18. Aouizerat BE, Miaskowski CA, Gay C, et al. Risk factors and symptoms associated with pain in HIV-infected adults. JAssoc Nurses AIDS Care. 2010;21(2):125-133.

19. Namisango E1, Harding R, Katabira ET, et al. A novel symptom cluster analysis among ambulatory HIV/AIDS patients in Uganda. AIDS Care. 2015;27(8):954-963.

20. Farrant L, GwytherL, Dinat N, Mmoledi K, Hatta N, Harding R. Maintaining wellbeing for South Africans receiving ART: the burden of pain and symptoms is greater with longer ART exposure. S Afr Med J. 2014;104(2):119-123.

21. Lawson E, Sabin C, Perry N, et al. Is HIV painful? An epidemiologic study of the prevalence and risk factors for pain in HIV-infected patients. Clin J Pain. Epub 2016 Oct 17.

22. Krashin DL, Merrill JO, Trescot AM. Opioids in the management of HIV-related pain. Pain Physician. 2012;15(Suppl 3):157-168.

23. Parker R, Jelsma J, Stein DJ. Pain in amaXhosa women living with HIV/ AIDS: translation and validation of the brief pain inventory-xhosa. $J$ Pain Symptom Manage. 2016;51(1):126-132.

24. Cleeland CS. The M. D. Anderson Symptom Inventory User Guide. Version 1, 2009. Available from https://www.mdanderson.org/documents/ Departments-and-Divisions/Symptom-Research/MDASI_userguide. pdf.

25. Merlin JS, Cen L, Praestgaard A, et al. Pain and physical and psychological symptoms in ambulatory HIV patients in the current treatment era. J Pain Symptom Management. 2012;43(3):638-645.

26. Merlin JS, Westfall AO, Raper JL, et al. Pain, mood, and substance abuse in HIV: implications for clinic visit utilization, antiretroviral therapy adherence, and virologic failure. J Acquir Immune Defic Syndr. 2012;61(2):164-170.

27. Bhengu BR, Ncama BP, Mclnerney PA, et al. symptoms experienced by HIV-infected Individuals on antiretroviral therapy in KwaZulu-Natal, South Africa. Appl Nursing Res. 2011;24(1):1-9.

28. Wahab KW, Salami AK. Pain as a symptom in patients living with HIV/ AIDS seen at the outpatient clinic of a Nigerian Tertiary Hospital. $J$ Int Assoc Physicians AIDS Care (Chic). 2010;10(1):35-39.

29. Jelly CA. Cross-Cultural Differences in Patient Perceptions and Outpatient Management of Chronic HIV/AIDS-related Pain; 2011. Duke University Libraries.

30. Norval DA. Symptoms and sites of pain experienced by AIDS patients. S Afr Med J. 2004;94(6):450-454.

31. Wright KP, Johnson JV. Evaluation of extended and continuous use oral contraceptives. Ther Clin Risk Manag. 2008;4(5):905-911.

32. Tsui JI, Cheng DM, Coleman SM, et al. Pain is associated with risky drinking over time among HIV-infected persons in St. Petersburg, Russia. Drug Alcohol Depend. 2014;144:87-92.

33. Bagby GJ, Amedee AM, Siggins RW, et al. Alcohol and HIV effects on the immune system. Alcohol Res. 2015;37(2):287-297.

34. Weatherburn TMP. Alcohol, AIDS and immunity. $\mathrm{Br}$ Med Bull. 1994;50(1):115-123.

35. Martin C, Pehrsson P, Osterberg A, Sonnerborg A, Hansson P. Pain in ambulatory HIV-infected patients with and without intravenous drug use. Eur J Pain. 1999;3(2):157-164.

36. Weinberg JL, Kovarik, CL. The WHO clinical staging system for HIV/ AIDS. AMA J Ethics. 2010;12(3):202-206.

37. Davis JA RR, Le TK, Xie J. incidence and impact of pain conditions and comorbid illness. J pain Res. 2011;4:331-345. 
The Journal of Pain Research is an international, peer reviewed, open access, online journal that welcomes laboratory and clinical findings in the fields of pain research and the prevention and management of pain. Original research, reviews, symposium reports, hypothesis formation and commentaries are all considered for publication
The manuscript management system is completely online and includes a very quick and fair peer-review system, which is all easy to use. Visit http://www.dovepress.com/testimonials.php to read real quotes from published authors. 